\title{
Mycological Studies on the Sputa of HIV Positive Clients Attending HIV Clinic in Federal Medical Centre Owerri, Nigeria
}

\author{
Nwako OF*, Mbata GC, Ofondu EU, Nwako AB, Dozie INS and Nwako CA
}

Department of Internal Medicine, FMC Owerri, Imo State, Nigeria

\begin{abstract}
Background: Human immune deficiency virus (HIV), the causative agent of Acquired Immune Deficiency Syndrome (AIDS) has remained a global cankerworm, with more impact in the sub-Saharan Africa. This virus destroys and depletes the human CD4 cells, leading to immune deficiency state and making the individual susceptible to opportunistic infections. Fungal opportunistic infections are among the common pathogens seen earlier in HIV positive individuals and may present as respiratory diseases like Pneumocystis jiroveci pneumonia and pulmonary cryptococcosis. This study aimed at understanding the pattern of fungal opportunists in the sputa of HIV positive individuals in our locality, to understand the demographics among those with the fungal isolates and to correlate CD4 level of the patients with the isolated opportunistic fungal pathogens.
\end{abstract}

Methods: This was a prospective study in design, study area was Federal Medical Centre Owerri, Imo state, Nigeria, and study population included HIV positive individuals who were older than fifteen (15) years who developed cough lasting for more than fourteen (14) days). The hospital is the largest in the state and serves some neighbouring states like Rivers, Anambra and Abia state. The sample size was seventy three (73). Samples were collected, processed and organisms identified and results tabulated.

Results: Out of the seventy three (73) sputa sample, 50 (68.5\%) showed positive growth while twenty three $23(31.5 \%)$ did not show any growth. Males with opportunistic fungal infections had a lower frequency $(40 \%)$ than females $(60 \%) .40 / 50(80 \%)$ of the grown organisms were Candida organism and $23 / 40(57.5 \%)$ of them were albicans. Candida albican had the highest incidence $23 / 50(46 \%)$ and seen more in the age bracket (25-34). It was also rarely seen when the CD4 cell count was more than $500 \mathrm{cell} / \mathrm{mm}^{3}$ but very common when count was $<400$ cells/ $\mathrm{mm}^{3}$. Cryptococcus neoformans had $5 / 50(10 \%)$ and isolated in individual with CD4 count $<100 \mathrm{cells} / \mathrm{mm}^{3}$, Aspergillus flavus and A. fumigatus were isolated at 56 and $367 \mathrm{cells} / \mathrm{mm}^{3}$ with incidences of $2.0 \%$ respectively (Figure 1). The Penicillium marneffi reported as the emerging fungal infection among HIV clients in Southeast Asia was not seen in our series.

Conclusions: Most pulmonary fungal opportunistic infection in the setting of HIV often mimics pulmonary tuberculosis. Candida albicans has the highest incidence in our study. However, knowledge of fungal opportunistic infections pattern in HIV patients will help clinicians in the appropriate management of the clients-in terms of prophylaxis and therapeutics.

Keywords: Mycology; Sputa; HIV; FMC Owerri; Nigeria

\section{Introduction}

Ever since the discovery of HIV about three decades back, it has remained a global cankerworm. AIDS, from HIV has resulted in about 20 million deaths; over 33 million people are living with HIV today and estimated 40 million children have one or both parents affected by AIDS [1]. This has amounted to significant decrease in Gross domestic product in some countries. Fungal opportunistic infections which are not often seen in the respiratory tract of immunocompetent individuals are one of the earlier symptoms presenting as a respiratory disease in immunocompromised persons [2] and some are even AIDS- Defining illness by WHO criteria (WHO, 2009). Pulmonary infection occurs after inhalation of spores/conidia, or by the reactivation of latent infection. Haematogenous dissemination of fungal infection leading to a systemic mycosis tends to occur chiefly in immunocompromised patients. Many of these opportunistic infections are serious and merit treatment; while some are preventable e.g. Pneumocystic jiroveci pneumonia, Candidiasis, Cryptococcus etc. The spectrum of fungal opportunistic infections in the sputa of HIV patients has been found to vary from place to place, Penicilium marneffi, being seen more in the South Eastern part of Asia, than any other region [3]. This organism is regarded as the emerging fungal opportunistic organism in areas where they are endemic and is the third commonest opportunistic organism after Mycobacterium tuberculosis and Cryptococcus [4]. To the best of our literary search, none has been reported so far for HIV cases in Nigeria. This work studied the pattern of fungal opportunistic organism in the sputa of those infected with HIV in our environment, correlating their CD4 level with the common isolates. Comparative analysis was done on those already on ART and on Non-ART. This work became necessary due to the under diagnosis of fungal opportunistic organism, which often mimic tuberculosis and may be a cause of morbidity and mortality among people living with HIV/AIDS. Candida albican has been implicated to be the cause of oropharyngeal, trachea and laryngeal candidosis. Our work was aimed at studying the pattern of fungal

*Corresponding author: Nwako Okechukwu Francis, Department of Medicine, FMC Owerri, Nigeria, Tel: +234-803-740-0054; E-mail: freeokey@yahoo.com

Received December 17, 2013; Accepted February 20, 2014; Published February 28, 2014

Citation: Nwako OF, Mbata GC, Ofondu EU, Nwako AB, Dozie INS, et al. (2014) Mycological Studies on the Sputa of HIV Positive Clients Attending HIV Clinic in Federal Medical Centre Owerri, Nigeria. J AIDS Clin Res 5: 286. doi:10.4172/2155 6113.1000286

Copyright: ( 2014 Nwako OF, et al. This is an open-access article distributed unde the terms of the Creative Commons Attribution License, which permits unrestricted use, distribution, and reproduction in any medium, provided the original author and source are credited. 


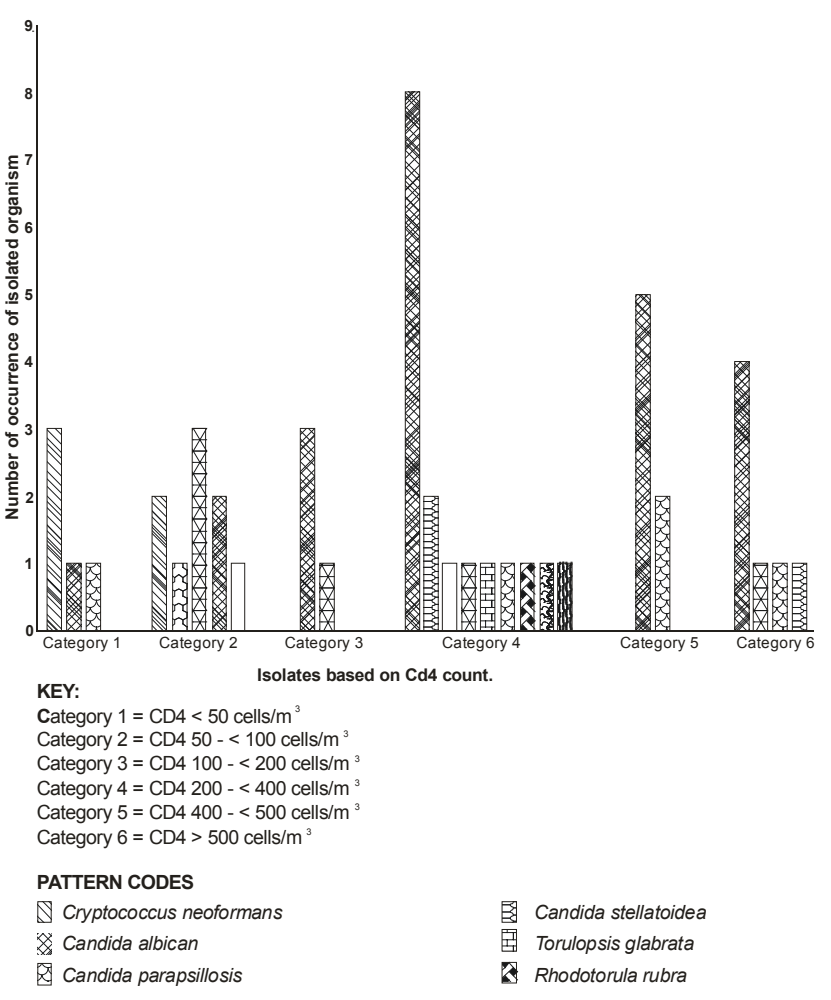

Figure 1: The relation of the $\mathrm{Cd} 4$ with the organisms isolated.

opportunistic infections in the sputa of HIV infected patients in our environment, correlating CD4+ level of the patients with the isolated opportunistic pathogens and understanding the demographics among those with the fungal isolates.

\section{Materials and Methods}

\section{Study area}

Seventy three samples from Federal Medical Centre Owerri, a tertiary health centre situate in Imo state, Nigeria, were analysed. The hospital serves Imo, Rivers, Abia and Anambra states and has capacity to manage about three thousand HIV positive patients.

\section{Study population}

This comprise adult HIV patients aged $>15$ years with history of chronic cough ie, more than two weeks. Participants were all drawn from HIV adult outpatient clinic. All data including HIV status and CD4 counts were performed by our laboratory and were collected from patients' folder/questionnnaire. We included ambulant HIV confirmed positive persons who were more than fifteen years of age, presenting with chronic cough, but smear negative TB, no radiological evidence of TB nor previously documented TB treatment. Patients not on any Angiotensin converting enzyme inhibitors and those who gave informed consent were recruited for the study.

\section{Sample collection}

Sputa were collected twice at 4 hourly-intervals in order to make sure that any isolated organism is principally resident in the sputum, using a wide mouthed sterile universal container after the client has gargled his/her mouth with water to reduce contaminants.

\section{Sample processing}

Samples collected were labelled properly and processed within 24 hours. Each sputum sample was inoculated onto four plates of Sabouraud Dextrose Agar (SDA); two with chloramphenicol and others without chloramphenicol. The plates were then incubated at $25^{\circ} \mathrm{C}$ and $37^{\circ} \mathrm{C}$ in order to get dimorphic fungi if they exist, for $24-72$ hours. After the incubation period, different colony types were noted and representative colony types were picked and sub-cultured on sterile SDA plates to obtain pure culture. The plates were incubated at $25^{\circ} \mathrm{C}$ and $37^{\circ} \mathrm{C}$ for 24 hours. Note that empty media were also cultured alongside the test medium at intervals to maintain quality assurance; however, the cultural environment will not support growth of contaminants.

\section{Identification of isolates}

Further studies were done with the pure isolates, like microscopy. Direct microscopy using $\mathrm{x} 10$ and $\mathrm{x} 40$ objective lens of the Microscope was done with the relevant stain (Lacto phenol Cotton Blue, 20\% Potassium Hydroxide (KOH) and Indian ink) on the samples and on pure cultures for adequate identification according to standard protocol [5]. Germ tube test (see appendix) was performed on all the yeast isolates to differentiate Candida albicans from all the other yeast forms. Picture of Cryptococcus neoformans is shown in Plate 1. The slide stains are also shown in Plate 2. The cultured isolates were destroyed by autoclaving to prevent spread of diseases.

\section{Interpretation}

Fungal organisms that appeared twice in the same patient sample were taken as an opportunistic pathogen and its presence was interpreted against the patient's immune status (CD4 cell count).

\section{Results}

A total of seventy three (73) samples were studied for the presence of fungal organisms in the sputa of HIV patients attending the HIV clinic of Federal Medical Centre Owerri. The following Tables 1-3 show the pattern of fungal isolates with other variables.

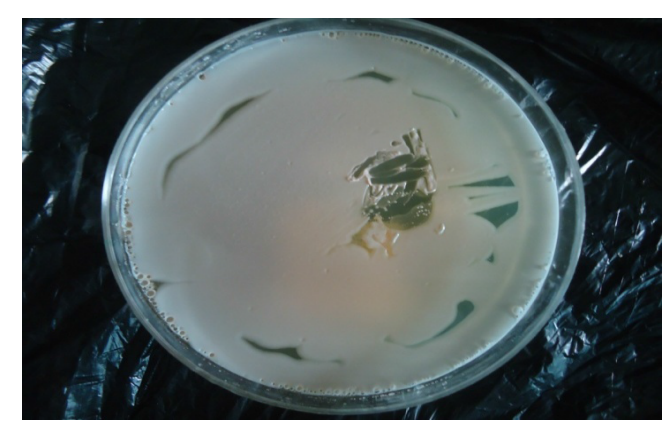

Plate 1: Cryptococcus neoformans (note the cream pink appearance).

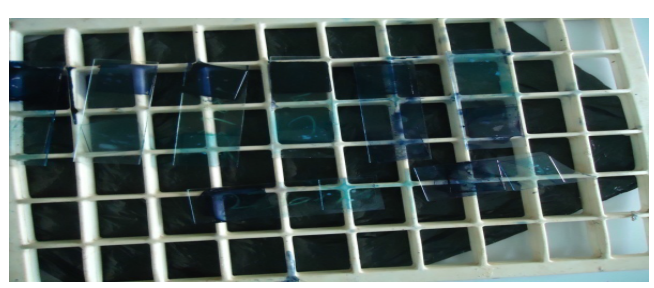

Plate 2: Different Stains on the slide for microscopy.

(Note the Lactophenol Cotton Blue and Indian ink stains). 
Page 3 of 5

\begin{tabular}{|l|c|c|}
\hline Name of organism & Number isolated & 23 \\
\hline Candida albicans & 5 & 46.0 \\
\hline Candida parapsillosis & 2 & 10.0 \\
\hline Candida krusei & 6 & 4.0 \\
\hline Candida tropicalis & 1 & 12.0 \\
\hline Aspergillus flavus & 1 & 2.0 \\
\hline Aspergillus fumigatus & 1 & 2.0 \\
\hline Rhodotorularubra & 5 & 2.0 \\
\hline Cryptococcus neoformans & 2 & 10.0 \\
\hline Torulopsis candida & 1 & \\
\hline Torulopsis glabrata & 3 & \\
\hline Candida stellatoidea & & \\
\hline
\end{tabular}

Table 1: Summary of isolated fungal organisms.

\begin{tabular}{|c|c|c|c|c|c|c|c|c|c|c|c|}
\hline \multirow[b]{2}{*}{ Age } & \multicolumn{11}{|c|}{ Fungal organisms } \\
\hline & $\begin{array}{l}\text { C. albicans. } \\
\mathrm{N}(\%)\end{array}$ & $\begin{array}{l}\text { C. tropicalis } \\
\mathrm{n}(\%)\end{array}$ & $\begin{array}{c}\text { C. neoformans } \\
\mathrm{n}(\%)\end{array}$ & $\begin{array}{c}\text { C. krusei } \\
\text { n (\%) }\end{array}$ & $\begin{array}{l}\text { R. rubra } \\
\mathrm{n}(\%)\end{array}$ & $\begin{array}{c}\text { C. parapsillosis } \\
\mathrm{n}(\%)\end{array}$ & $\begin{array}{l}\text { T. glabrata } \\
\text { n (\%) }\end{array}$ & $\begin{array}{l}\text { T. candida } \\
\mathrm{n}(\%)\end{array}$ & $\begin{array}{c}\text { A. flavus } \\
\mathrm{n}(\%)\end{array}$ & $\begin{array}{l}\text { A. fumigates } \\
\mathrm{n}(\%)\end{array}$ & $\begin{array}{c}\text { C. stellatoidea } \\
\mathrm{n}(\%)\end{array}$ \\
\hline $15-24$ & 6 & 1 & 1 & - & - & 2 & - & - & - & - & 2 \\
\hline $25-34$ & 8 & 2 & 1 & - & 1 & 2 & - & - & - & - & - \\
\hline $35-44$ & 2 & - & 1 & 2 & - & - & - & - & - & - & - \\
\hline $45-54$ & 5 & 1 & 2 & - & - & 1 & 1 & - & - & - & 1 \\
\hline$>55$ & 2 & 2 & - & - & - & - & - & 2 & - & 1 & 1 \\
\hline
\end{tabular}

Table 2: Age-related prevalence and fungal isolates.

\begin{tabular}{|c|c|c|c|c|c|}
\hline$<50$ cells $/ \mathrm{mm} 3$ & $50-<100$ cells $/ \mathrm{mm} 3$ & $100-<200$ cells $/ \mathrm{mm} 3$ & $200-<400$ cells $/ \mathrm{mm} 3$ & $400-<500$ cells $/ \mathrm{mm} 3$ & $>500 \mathrm{cells} / \mathrm{mm} 3$ \\
\hline C. neoformans (3) & C. neoformans (2) & C.albicans (4) & C. albicans (8) & C. albicans (5) & C. stellatoidea (1) \\
\hline T. candida (1) & A. flavus (1) & C. tropicalis (1) & C. krusei (1) & C. parapsillosis (2) & C. albicans (4) \\
\hline C. parapsillosis (1) & C. tropicalis (3) & & C. tropicalis (1) & C. parapsillosis (1) \\
\hline & C. albicans (2) & & Aspergillusfumigatus (1) & C. tropicalis (1) \\
\hline & C. krusei (1) & & C. stellatoidea (2) & \\
\hline & & & T. glabrata (1) & \\
\hline & & T. candida (1) & \\
\hline & & C. parapsillosi (1) & \\
\hline & & R. rubra (1) & \\
\hline
\end{tabular}

Table 3: CD4 count in relation to the isolated organisms.

\section{Discussion and Conclusion}

The aims of our study were to determine the common fungal opportunistic infections in our environment, to establish a relationship between the CD4 of patient and the fungal isolate and to determine the patients' demographic relationship with the fungal isolates. A total of seventy three (73) patients' sputa were studied out of which 23 sputa did not grow any organism, while fifty (50) showed positive growth. Just like many other related study in the world [6] ours showed that Candida albicans has the highest incidence as common organism causing fungal opportunistic infections among HIV/AIDS clients in our environment. This is in agreement with work done by [7] Melody who reported similar experience. Incidence is approximately $46 \%$ (Table 1 ). Kumarasamy et al. [8] and Misra et al. [9] reported some non-albican candida as emerging candidal spp seen as opportunistic organisms among HIV clients. Melody [7] also reported such candida spp as we did but noted that they were less frequently involved in diseases. Such organisms were isolated as well, like the C. tropicalis, C. krusei and C. Parapsillosis (Table 1). Species differentiation is important as some are known to be resistant to most often used antifugals like fluconazole. Patients aged 25-34 years had highest incidence of C. albicans (34.7\%) (Table 2). Candida albicans was rarely associated with clients whose CD4 counts were $>500$ cells/ $\mathrm{mm}^{3}$; however, at $\mathrm{CD} 4<400$, the occurrence was remarkably high (Table 3 ). Of the 50 positive growth from the patients, 40 patients sample (80\%) were candida and 24 clients $(60 \%)$ were on antiretroviral therapy while $16(40 \%)$ have not been commenced on drugs as ART should improve the CD4 level, thus reducing the possibilities of opportunistic organisms. The reversal of the result is though explainable in our work since most of the patients with fungal opportunistic organisms manifested when their CD4 were less than $400 / \mathrm{mm}^{3}$, a level at which ART is commenced in our centre ie $\mathrm{WHO}<$ or $=350 / \mathrm{mm}^{3}$. Out of the $80 \%$ that demonstrated candidal growth, $57.5 \%$ were albican. Candida albicans has been implicated as the aetiologic agent of candidiasis in immunocompromised and immunocompetent individuals, especially HIV/AIDS. This disease can present as a local or disseminated candidiasis. Locally, patients may present with esophageal candidiasis, oral candidiasis (Thrush). The hallmark of this is a white plaque on the mucosa of the buccal cavity, which will usually bleed on scrapping with a tongue depressor [7]. Diagnosis of candidiasis is both clinical and laboratory. $\mathrm{KOH}$ slide preparation, although not mandatory, can confirm the diagnosis, demonstrating characteristic pseudohyphae and spherical budding yeast. There are many options available for treatment of forms of candidiasis. Options for treatment of non-complicated disease include local and systemic therapies with the use of azole 
antifungal like fluconazole and Itraconazole and the polyene antifungals like the Nystatin. Clinical response to initial treatment is seen with most agents. Factors that determine response include choice of agent, extent and severity of infection, adherence to regimen, and pharmacokinetic and pharmacodynamic properties of the drug. Because of the concern over azole resistance and the limitations with antifungals currently used for refractory disease, new azole antifungals with activity against fluconazole-resistant strains of Candida species are being developed. Voriconazole and caspofungin are more recent additions to the antifungal armamentarium, while posaconazole, ravuconazole, and anidulafungin are actively being developed. Micafungin (Mycamine), an agent in a new class of antifungals known as echinocandins, has recently been approved and is available in an IV formulation. All of these agents have demonstrated in vitro activity against Candida species. Voriconazole (Vfend) was approved in the United States in 2002 and is available in both oral and IV formulations. Voriconazole has demonstrated equivalence to fluconazole for treatment of esophageal candidiasis, although it was associated with more toxicity [10]. Despite these added toxicities, treatment of fluconazole-resistant strains with voriconazole has shown some success, and use of this agent in resistant cases of disease may be warranted [11]. Voriconazole is currently not licensed for this indication in the United States, awaiting additional data from on-going clinical trials. Caspofungin, a member of a novel class of antifungals known as candins, is a parenterally administered drug that has demonstrated activity against Candida species, including fluconazole resistant organisms [6]. In all our patients, none was on antifungal because of the inclusion criteria to avoid bias.

Cryptococcosis is an AIDS defining illness, WHO stage IV, and caused by Cryptococcus neoformans, an opportunistic fungal infection, often seen in the immunocompromised. It is the second commonest opportunistic infection after tuberculosis in south East Asia [12]. Cryptococcosis may manifest as meningitis or as a cause of bronchopneumonia, with mortality $>50 \%$ if untreated. Incidence varies from 4-7 \% among Africans and $<1 \%$ in developed countries like Thailand. In our study, we got an incidence of $10 \%$ (Table 2), which is slightly above the WHO estimate. Studies done by many researchers has placed the CD4 at manifestation of Cryptococcus disease at $<100$ cell $/ \mathrm{mm}^{3}$, we support this, as all our study samples showed CD $4<100$ cells $/ \mathrm{mm}^{3}$ (Table 3). However, researchers like Fichtenbaum [13] maintained that the CD4 at greatest risk is less than 50 counts $/ \mathrm{mm}^{3}$. Pathogenic role of the isolate need to be established by production of melanin; surprisingly, recent study done in India by Uma [12] showed that both melanin positive and negative isolates were seen together on a patient with chronic meningitis. This has significantly thrown a scientific debate on the role of melanin test to confirm pathogenicity. We considered that our participants, who had chronic cough with positive culture of Cryptococcus, may likely be due to this agent and may have pulmonary cryptococcosis. However, the commonest presentation of Cryptococcosis in HIV positive clients is meningitis [14]. Cutaneous cryptococcal infection is usually a sign of disseminated disease. Lesions can vary and may present as pustules, vesicles, plaques, or subcutaneous swelling. The most typical presentation appears similar to the dermatologic features of Molluscumn contagiosum [15]. Diagnosis of Cryptococcus has been with the use of Indian ink stain which will reveal encapsulated yeast with a halo, [5] with a positive culture for confirmation. Yield with Indian ink is more than $95 \%$ sensitive. The use of antigen serology for the capsular polysaccharide is said to be up to $99 \%$ sensitive [7]. In our study, our Cryptococcus was identified after culture and staining of the colony with Indian ink, with the characteristic encapsulated yeast with a halo. Our organism was not sero-typed to identify the particular serotype. Drug treatment of Cryptococcus has been categorised into three phases viz: Induction, Consolidation and Maintainance. Amphotericin B +/- Flucytosine is used for the induction phase while Fluconazole is used both for consolidation and maintainance phase [16].

Aspergillus fumigatus and A. Flavus were isolated from two clients at CD4 367 and 56 cells $/ \mathrm{mm}^{3}$ respectively. Aspergillosis in HIV clients as a co-infection is very rare and has an incidence of 1.1-3.5 episodes per 1000 person years. Mortality is also very high. Our work, revealed an incidence of $2 \%$ (Table 1) for each of the isolate. Aspergillosis often mimics tuberculosis, presenting with heamoptysis, cough, dyspnoea and cavities on X-Rays (fungal balls). Diagnosis of aspergillosis requires host factors, clinical/radiological factors [5]. Treatment of Aspergillosis in HIV has been said to be difficult unless the neutrophil is sustained, often with granulocyte colony-stimulating factors. Capsofungin is also effective [14]. In our study the two of the patients were females and were more than fifty five years. We isolated two (2) Torulopsis spp (candida and glabrata) with CD4 count of occurrence $<400$ cells $/ \mathrm{mm}^{3}$. The overall incidence was about $6 \%$. Report on Torulopsis and HIV is scanty. Sunita and Mahendra [17] in his study on 'Emerging of Mycotic Infection in Patients Infected with Mycobacterium tuberculosis noticed that the frequency of opportunistic and human pathogenic fungi was higher in male (62.50\%) as compared to female (37.5\%). Though our study is on HIV patients, we tend to have a different finding where males with opportunistic fungal infections had a lower frequency (40\%) than females (60\%). Interestingly, our observation did not agree with Mandanas [18] who explained that endemic fungal infections seem to be more common in men than women as oestrogen is thought to exert an inhibitory effect on the growth cycle of fungi. The highest age distribution range for opportunistic fungal infection in Sunita and Mahendra (2008) study (35-44 years) represented our least age of opportunistic fungal infection, while our highest age for opportunistic infection ranged between 25-34 years. Differences in these studies may be due to the primary illness studied, presence of ART or geographical. From our work, we noticed that it is worth mentioning that the CDC Atlanta Georgia classification of HIV 1993, which took cognisance of the laboratory and clinical axis, seemed more to be representing the patients' status, than the WHO classification, which is based on clinical axis alone. We think that the logic of the WHO classification was based on the assumption that the lower the CD4, the worse the symptoms. In practice patients with low CD4 but no symptom are umpteen times seen, but this does not mean that they are well! Most of the fungal opportunistic organisms were evident when the CD4 counts were $<400$ cells $/ \mathrm{mm}^{3}$ (Table 3). This calls for prophylactic anti fungals to be part of the protocol in the overall management of patients with HIV when the CD4 gets that low. Perhaps, the CD4 count for ART commencement may need to be upwardly set! This, if implemented will reduce the burden of fungal opportunistic organisms among HIV positive clients, leading to increased quality of life. Most fungi are not known to be pathogenic in immuno-competent persons; however, with the advent of immunosuppression from HIV, the fungal opportunistic organisms have assumed great importance in the recent past. The fungal opportunistic organisms are generally associated with $>50 \%$ mortality, yet some are preventable by prophylaxis. Working knowledge of the fungal profile in our environment and patients will help the clinician in the appropriate management of the clients-in terms of prophylaxis and therapeutics. As the common CD4 counts for occurrence of some fungal opportunistic organisms have been established in our setting; the need for timely prophylactic antifungal may not be overlooked. Most fungal infections present in a similar way to pulmonary tuberculosis. 
Chest X-rays also look similar [17]. TB/HIV patients have few AFB in their sputum making Ziehl Neelsen Technique less sensitive (20-30\% true positive). Again, since the diagnosis of drug resistance and multi drug resistance is not easily made objectively in our environment, one wonders if the drug resistant and multidrug resistant TB were not fungal opportunistic infections as our study clearly shows that our studied patients had chronic cough, a strong symptom of $\mathrm{TB}$, which often times qualify patients as a TB suspects. Our study shows that lower CD4+ count was associated with those pulmonary fungal OIs known to increase morbidity in immune-suppressed individuals and this should be a strong differential in any patient with CD4+ cell count less than $200 / \mathrm{mm}^{3}$ with chronic cough. Clinicians therefore will need to liaise with the medical microbiologist for more mycological diagnosis as this may be life saving.

\section{References}

1. UNAIDS (2008) Reports on the global AIDS epidemics. Washington DC, USA.

2. Jawetz Melnick, Adelberg (2010) Textbook of medical microbiology. (25thedn), McGraw-Hill publishers.

3. Anarparthy U, Bharathi M (2011) Penicillium marneffei-AIDS Defining illness. $N$ Dermatol Onlin 2: 58-60.

4. Jagdish Chander (2009) Textbook of medical mycology. (3rdedn), published by Mehtha publications 23: 329-330.

5. WHO (2009) laboratory manual for the diagnosis of fungal opportunistic infections in HIV/TB patients.

6. Kartsonis N, DiNubile MJ, Bartizal K, Hicks PS, Ryan D, et al. (2002) Efficacy of caspofungin in the treatment of esophageal candidiasis resistant to fluconazole. Journal of Acquired Immune Deficiency Syndrome Human Retrovirology 31: 183-187.

7. Melody L Duffalo (2006) Fungal Opportunistic Infections in HIV Disease Journal of Pharmacy Practice 19: 17-30.
8. Kumarasamy N, Solomon S, Jayaker Paul SA, Venilla R, Amalraj RE (1995) Spectrum of opportunistic infections among AIDS patients in Tamil Nadu, India. Int J STD AIDS 6: 447-449.

9. Misra SN, Sengupta D, Satpathy SK (1998) AIDS in India: recent trends in opportunistic infections. Southeast Asian J Trop Med Public Health 29: 373376.

10. Ally R, Schürmann D, Kreisel W, Carosi G, Aguirrebengoa K, et al. (2001) A randomized, double-blind, double-dummy, multicenter trial of voriconazole and fluconazole in the treatment of esophageal candidiasis in immunocompromised patients. Clin Infect Dis 33: 1447-1454.

11. Hegener P, Troke PF, Fätkenheuer G, Diehl V, Ruhnke M (1998) Treatment of fluconazole-resistant candidiasis with voriconazole in patients with AIDS. AIDS 12: $2227-2228$.

12. Banerjee U (2005) Progress in diagnosis of opportunistic infections in HIV/ AIDS. Indian J Med Res 121: 395-406.

13. Fichtenbaum CJ, Candidiasis (2003) In: Dolin R, Masur H, SaagM (eds.), AIDS Therapy. (2ndedn), Churchill-Livingstone, Philadelphia, Pa, USA 531-542.

14. Kumar P, Clark M (2009) Clinical Medicine. (7thedn), Sunders Elsevier Published, 200-202.

15. Concus AP, Helfand RF, Imber MJ, Lerner EA, Sharpe RJ (1988) Cutaneous cryptococcosis mimicking molluscum contagiosum in a patient with AIDS. J Infect Dis 158: 897-898.

16. Saag MS, Graybill RJ, Larsen RA, Pappas PG, Perfect JR, et al. (2000) Practice guidelines for the management of cryptococcal disease. Infectious Diseases Society of America. Clin Infect Dis 30: 710-718.

17. Sunita Bansod, Mahendra Rai (2008) Emerging mycotic infection in patients infected with Mycobacterium tuberculosis. World Journal of Medical Sciences 3: $74-80$.

18. Mandanas R (2007) Overview of Fungal Pneumonia 